\title{
Antler velvet is thicker in adult than in yearling pampas deer (Ozotoceros bezoarticus): a histological study
}

\author{
A. Bielli ${ }^{1}$, A. Freitas-de-Melo², P. Genovese ${ }^{1}$, M. Villagrán ${ }^{3}$, R. Ungerfeld ${ }^{3}$ \\ ${ }^{1}$ Departamento de Morfología y Desarrollo, Facultad de Veterinaria, Universidad de la República, \\ Lasplaces 1550, Montevideo, Uruguay \\ 2Departamento de Biología Molecular y Celular, Facultad de Veterinaria, Universidad de la República, \\ Lasplaces 1550, Montevideo, Uruguay \\ ${ }^{3}$ Departamento de Fisiología, Facultad de Veterinaria, Lasplaces 1550, Montevideo, Uruguay
}

[Received: 29 July 2016; Accepted: 2 October 2016]

Background: Antlers are lined by soft velvet tissue during antler growth. Later, the velvet is shed before rut onset. There are no detailed histological descriptions of the growing velvet, nor whether the velvet changes according to stag age. Our aims were to: 1) describe the basic histology of pampas deer antler velvet from adult and yearling males; and 2) determine the influence of age and time of antler growth on velvet's tissues morphometry.

Materials and methods: Samples were collected from 10 stags allocated in two groups, either adult (3-5 years old, $n=5$ ) or yearling males ( 2 years old, $n=5$ ). The day of antler cast was recorded for each animal. In spring, the stags were anaesthetised and velvet samples were collected from the third tine's distal end. Samples were described qualitatively and a restricted morphometrical analysis of the antler velvet was performed.

Results: The number of keratinocyte layers and the thicknesses of: total epidermis, corneum, intermediate and basale epidermal strata, total dermis, superficial and deep dermis were determined. Age and days after antler casting positively influenced in conjunction epidermal thickness ( $p=0.037)$, and tended to influence both stratum intermedium $(p=0.076)$ and stratum corneum $(p=0.1)$ thicknesses. Age influenced stratum corneum thickness $(p=0.04)$. The pampas deer antler velvet lacked both sweat glands and arrector pili muscles.

Conclusions: The deep dermis was densely irrigated but displayed abundant and well developed collagen bundles. Both total epidermal and stratum corneum thicknesses related positively to the age of the animals but were not to the time since antler cast. (Folia Morphol 2017; 76, 2: 269-276)

Key words: cervid, skin, histology, morphometry, growing antler

\section{INTRODUCTION}

Most deer species display a seasonal reproductive pattern, with parturitions occurring mainly in spring [6]. Deer males' antler cycle is closely related to the annual changes in testosterone concentrations [3]. During the non-breeding season, testosterone concentration decreases to basal values lowest and antlers are cast. After this, new antlers grow enveloped

Address for correspondence: A. Bielli, PhD, Departamento de Morfología y Desarrollo, Facultad de Veterinaria, Universidad de la República, Lasplaces 1550, Montevideo 11600, Uruguay, e-mail: biellialejandro@gmail.com 
by soft velvet-like skin (antler velvet [AV]) until antler's growth and calcification ends [14]. Antler nerves grow through the velvet in close association to blood vessels in an environment rich in growth promoting molecules [20]. The AV is shed in coincidence with a great increase in testosterone concentration occurring before the rut onset $[19,21]$.

The AV has elicited scientific interest as a promise for several health treatments $[11,13,18,32]$. For example, AV is a potential therapeutic agent for managing osteoporosis in rats $[24,25]$, or is capable of inducing and guiding neurite outgrowth of rat sensory neurons in vitro [20]. Total velvetantler polypeptide extracts have been shown to promote proliferation of human peripheral blood lymphocyte cells [33]. Moreover, AV is a main product of deer farms which is used as a general health benefit: for example in Australia it is considered a food supplement, and in Asia it is a fundamental component of Traditional Chinese Medicine [5, 30]. $\mathrm{Li}$ and Suttie [15] described the histology of the pedicle skin formation and its transformation to AV. Surprisingly, although there are several studies regarding velvet constituents $[1,16,23,24,34]$, we could not find any detailed histological characterisation of the AV.

The pampas deer (Ozotoceros bezoarticus, Linnaeus, 1758) is an endangered species, originally distributed in the open grasslands (pampas) across eastern South America [12]. Nowadays, few small populations remain in Argentina, Brazil and Uruguay [26]. Pampas deer semicaptive breeding started in 1981 at the Estación de Cría de Fauna Autóctona Cerro Pan de Azúcar (ECFA, Uruguay) [26]. In the pampas deer allocated at the ECFA, antler cast occurs in mid-winter [27]. Furthermore, antlers casts were observed earlier in adult than in juvenile males displaying their first antlers [27] while the antler weight/ body weight rate is higher in adult than in juvenile males, indicating that adults invest more resources in antler growth [29].

Testosterone concentrations, and antlers' size and weight increase annually until males are at least 5 years old [29]. As antler size is directly linked to both age and body size in red deer [7, 17] and both antler and velvet developments are closely related, it may be expected that velvet morphological characteristics also vary with males' age. Similarly, histological skin thickness is related to age, as atrophy of the dermis and the epidermal depth increases with age in several mammals [2], but skin thickness and collagen fibre density increases with age in both sexes up to adult life, and decreases thereafter [31].

Therefore, our aims were to: 1 ) describe the basic histology of pampas deer AV from adult and yearling males; 2) determine the influence of age and time of antler growth on morphometrical characteristics of AV from pampas deer males.

\section{MATERIALS AND METHODS}

All the procedures were approved by the Comisión Honoraria de Experimentación Animal of the Facultad de Veterinaria, Universidad de la República, Uruguay.

\section{Animals and location}

The study was performed at the ECFA, where animals had been allocated either in breeding groups (1 stag and 5-10 hinds) or in stags-only groups on paddocks of 0.5-1 ha for many years. For this study, we used 10 stags allocated in two groups, one of adult ( $3-5$ years, $n=5$ ) and one of juveniles ( 2 years, $n=5)$. Each group was allocated on one paddock since at least 6 months before the study started. Animals grazed over native pastures, browsed trees and shrubs, received daily approximately $500-600 \mathrm{~g}$ of dairy cows ration/deer and had free access to water.

\section{Sampling procedures, qualitative and quantitative histological analysis}

The day of antler cast was recorded for each animal from July to early September (winter-early spring). Velvet samples were collected in early October. Adult and yearling stags casted their antlers $67.0 \pm 7.5$ (mean \pm SEM) (range: 62-81 days) and $50.0 \pm 4.0$ days (range: 31-75 days) before sampling, respectively. The day of antler cast of one adult stag was not recorded, so its data was not considered for the quantitative analysis. The animals were anesthetised according to Fumagalli et al. [10], with anaesthetic darts containing xylazine 10\% (Sedomin; Laboratorio König, Buenos Aires, Argentina), $1.6 \mathrm{mg} / \mathrm{kg}$ of ketamine 5\% (Vetanarcol; Laboratorio König) and $0.013 \mathrm{mgkg}$ of and atropine darts containing xylazine 10\% (Sedomin; Laboratorio König, Buenos Aires, Argentina), $1.6 \mathrm{mgkg}$ of ketamine 5\% (Vetanarcol; Laboratorio König) and $0.013 \mathrm{mg} / \mathrm{kg}$ of and atropine $1 \%$ (Sulfato de Atropina; Laboratorio ION, Montevideo, Uruguay) fired from a blowpipe (Telinject, California, USA). Anesthetised deer were transported to the veterinary facilities, and placed in right lateral 
recumbency on a padded table. An intravenous catheter was placed into the cephalic vein, and sodium chloride $0.9 \%$ was continuously administered. This via was also used when anaesthetic reinforcement was required.

Velvet samples were collected from the third tine's (the most distal one, see [28]) distal end, immediately proximal (beginning at approximately $1.5 \mathrm{~cm}$ ) to the soft, cartilaginous tip. A velvet strip, approximately $1.5 \mathrm{~cm}$ long and $0.7-1.0 \mathrm{~cm}$ wide, was taken longitudinally along the lateral side of the antler. The velvet sample was immersed immediately in Bouin's solution and later dehydrated in increasingly concentrated ethanol $\left(70^{\circ}, 90^{\circ}\right.$ and $\left.100^{\circ}\right)$, dehydrated in xylene, and embedded in paraffin wax. Sections $(6 \mu \mathrm{m})$ cut perpendicular to the longitudinal axis of the antler were stained either with haematoxylin-eosin and with Van Gieson's stain. Stained sections were carefully inspected to provide a qualitative description of the AV.

Thereafter, a restricted morphometric analysis of the $A V$ was performed. Fifty to eighty images from haematoxylin-eosin stained sections were captured from a light microscope (BX50, Olympus) using a video camera (SSC-C158, Sony, Tokyo, Japan) and analysed with Infinity Analyse software (Lumenera Corporation, Ontario, Canada) at a final magnification of $600 \times$. Total epidermal thickness, thickness of the corneum, intermediate and basale strata of the epidermis, total dermis thickness, superficial and deep dermis thickness, and the number of keratinocyte layers were measured.

\section{Statistical analysis}

Quantitative histological variables were compared between yearling and adult stags using ANOVA, including the days since antler cast as a coverable in the model. A multiple regression analysis was performed considering the age of each deer and the number of days since antler cast as independent variables, and the quantitative histological variables as the dependent variables. Data are presented as mean \pm standard error of mean (SEM).

\section{RESULTS}

\section{Qualitative histological analysis}

\section{Haematoxylin-eosin stain}

The AV of pampas deer had the same general characteristics of the mammalian thin skin. The most remarkable characteristic was the absence of sweat

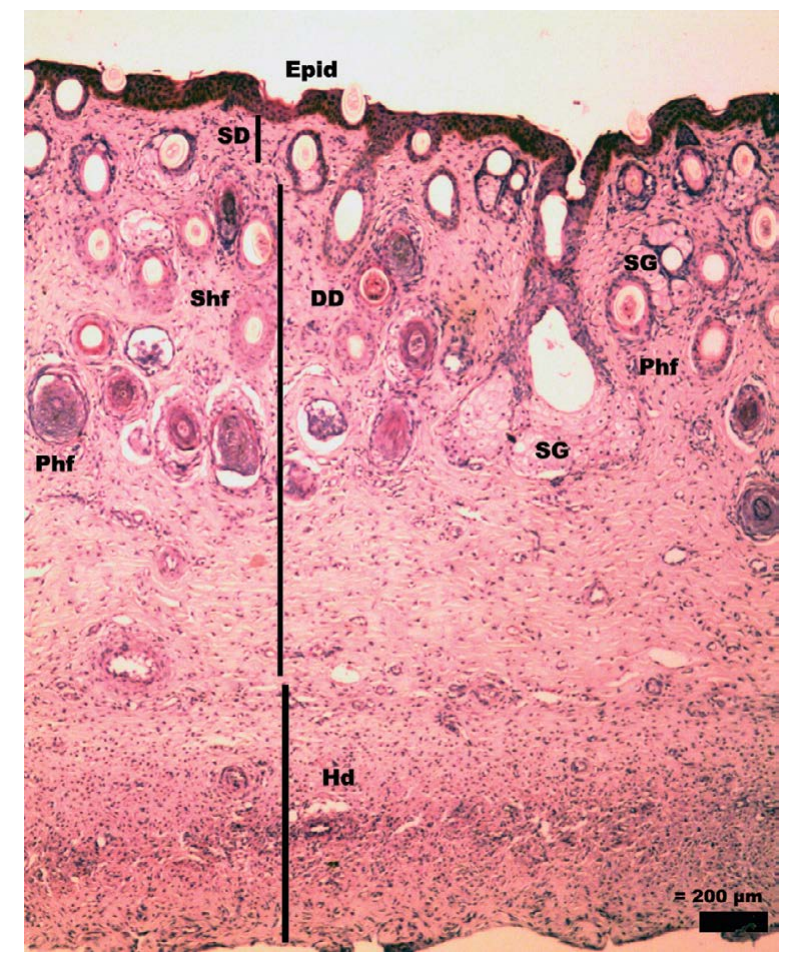

Figure 1. Antler velvet from juvenile pampas deer (Ozotoceros bezoarticus) males, general view. Epid - epidermis; SD superficial dermis; DD — deep dermis; Hd - hypodermis; Phf — primary hair follicle; Shf — secondary hair follicle; SG — sebaceous gland. Magnification: $\times 40$. Bar $=200 \mu \mathrm{m}$.

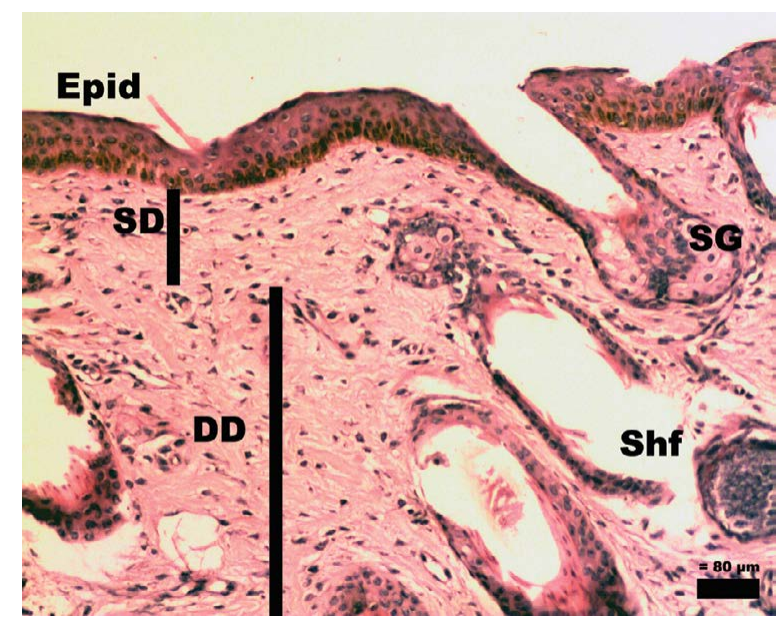

Figure 2. Antler velvet from adult deer, general view. Note deep primary follicle with very well developed sebaceous gland. Epid epidermis; SD - superficial dermis; DD - deep dermis; Hd hypodermis; Shf — secondary hair follicle; SG — sebaceous gland. Magnification: $\times 100$. Bar $=80 \mu \mathrm{m}$.

glands and arrector pili muscles. Three layers could be recognised: epidermis, dermis (both superficial and deep) and hypodermis (Figs. 1, 2). Several particulari- 
ties of each layer could be pointed out, which will be described below.

In most samples, there were no dermal papillae penetrating the epidermis. Variations in epidermal thickness were quite evident, with alternating thinner and thicker sectors, which made the dermo-epidermal limit an undulating profile. The stratum basale (one cell thick) of the epidermis was composed of low columnar epithelial cells (keratinocytes) and melanocytes (Fig. 3).

Melanin was visible and abundant. Superficially to the basal stratum, a spinosum stratum could be recognised; it had a pair of cells thick, made up of polyhedral to rhomboidal keratinocytes, with their longer axis perpendicular to the epidermal surface. A stratum granulosum, also a pair of cells thick and with few granules, was closer to the skin surface. Keratinocytes were also polyhedral, but the longer axis was parallel to the epidermal surface in stratum granulosum. The most superficial stratum was stratum corneum, 2-3 squamous keratinocytes thick. The most superficial cells seemed highly keratinised, but their nuclei were still recognisable.

The dermis could be subdivided into a thin superficial stratum (superficial dermis), 5-10 cells thick, with a very dense microvascular bed (arterioles, venules, capillaries), and thin collagen bundles. The deep dermal stratum (deep dermis) was much thicker, and occupied most of the velvet thickness. Blood vessels were also very abundant, but besides a dense microvascular bed, there were arteries and veins of bigger diameter, as well as conspicuous lymph vessels and nerves. Hair follicles were abundant. It was easy to distinguish between primary and secondary hair follicles. Primary follicles were longer and with bigger diameter, with a pair of well-developed sebaceous glands. Secondary hair follicles were more abundant but shorter, of smaller diameter, and with small sebaceous glands. Primary hair follicles reached the deepest portion of the deep dermis (Fig. 4), whereas secondary hair follicles reached approximately twothirds of such depth. As in all mammalian skin types, primary hair follicles could be recognised because of their bigger diameter, both at the stem and at the follicle bulb. The capillary bundle at the follicle bulb axis was longer and wider in primary follicles. Furthermore, keratinocytes looked bigger and darker stained in primary follicle bulbs. Two kinds of primary hair follicles could be distinguished: a few longer follicles, with deeper bulbs, bigger diameter and very big

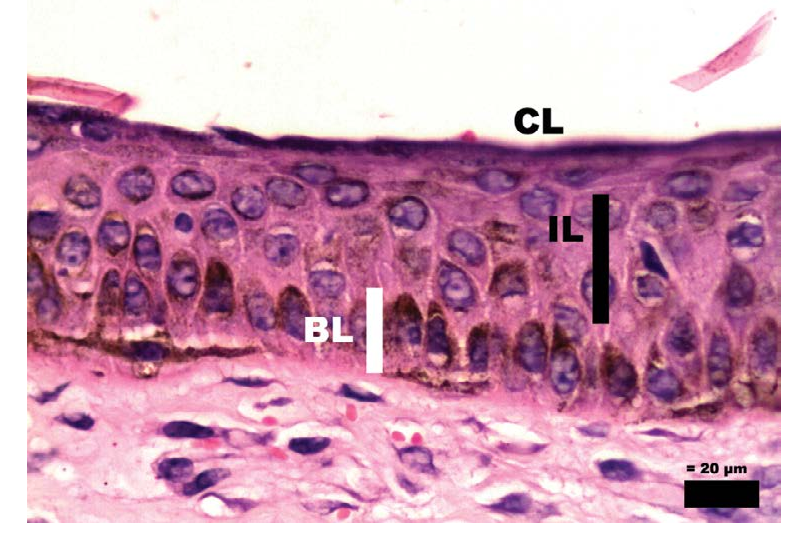

Figure 3. Epidermis, adult deer. Note abundant melanocytes in basal layer (BL), and melanin-rich keratinocytes throughout the epidermis. IL - intermediate layer; $\mathrm{CL}$ - corneal layer. Magnification: $\times 400$. Bar $=20 \mu \mathrm{m}$

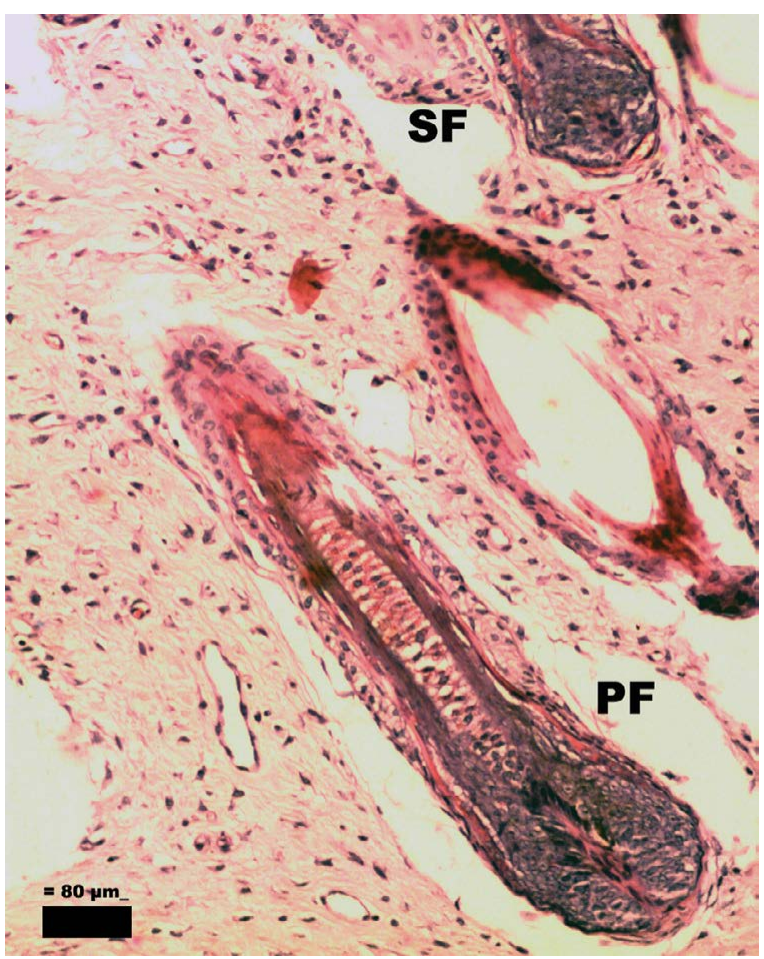

Figure 4. Deep dermis, adult deer. Note wider follicle bulb and longer capillary bundle in primary hair follicle (PF). See follicle bulb, capillary bundle, hair follicle stem, and cuticle, cortex, medulla of hair fibre; SF - secondary hair follicle. Magnification: $\times 100$. Bar $=80 \mu \mathrm{m}$.

and deeply located sebaceous glands, as compared to most primary follicles. No sweat glands or arrector pili muscles were seen. The hair fibres of primary follicles had a superficial thin and keratinised cuticle, 


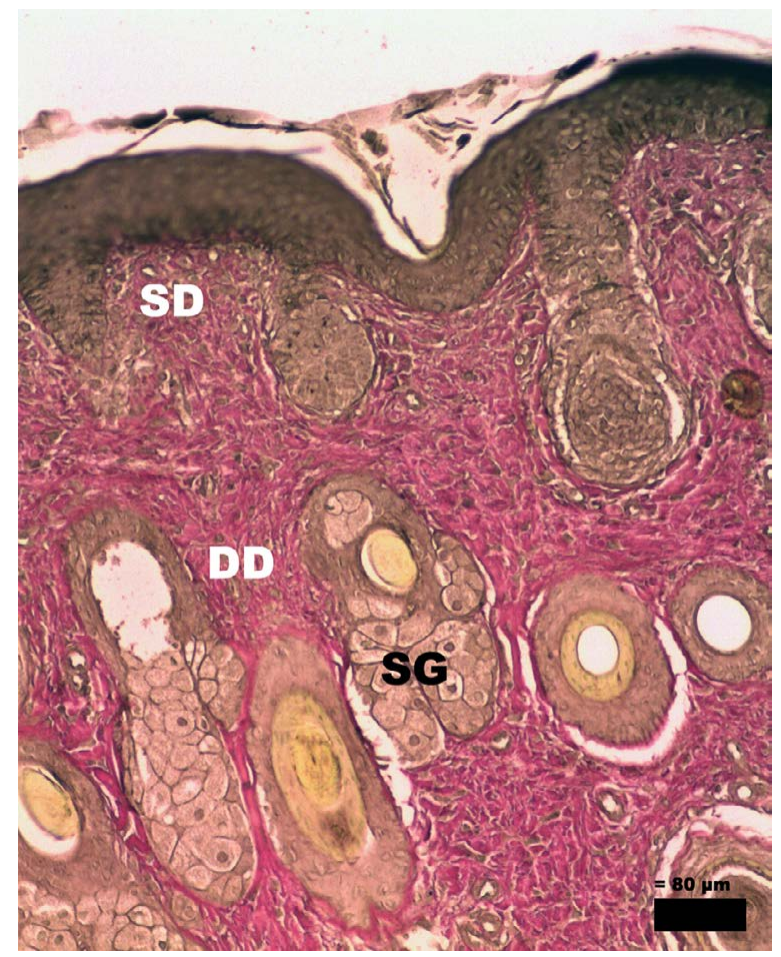

Figure 5. Antler velvet, Van Gieson's stain. Note thicker collagen bundles in deep dermis (DD), how collagen bundles direction changes between superficial dermis (SD) and DD, sloughed off corneal stratum; SG - sebaceous gland. Magnification: $\times 100$. Bar $=80 \mu \mathrm{m}$.

a thick, keratin-rich looking cortex, and a narrow medulla. The hair fibres in secondary follicles had a markedly smaller diameter, the cortex was much thinner. However, the medulla's diameter was similar to the primary hair fibres. A couple of secondary follicles were seen reaching the epidermal surface at the same pore as a primary follicle.

Deeper beyond the dermis lay the hypodermis: a thick, dense, connective tissue layer. This hypodermal layer was more fibrous than the deep dermis, and more densely irrigated than the deep dermis, especially regarding thick veins. The hypodermal layer seemed thicker in most adult than in yearling stags.

\section{Van Gieson's stain}

Using the Van Gieson's stain, abundant collagen bundles were evident in both superficial and deep dermis (Fig. 5). Collagen bundles in the superficial dermis were thinner than in the deep dermis. Collagen bundles were particularly thin in the shallow dermal superficial papillae which were visible in thicker epidermis' areas. In the deep dermis, collagen bundles were abundant and much thicker than in the superfi-

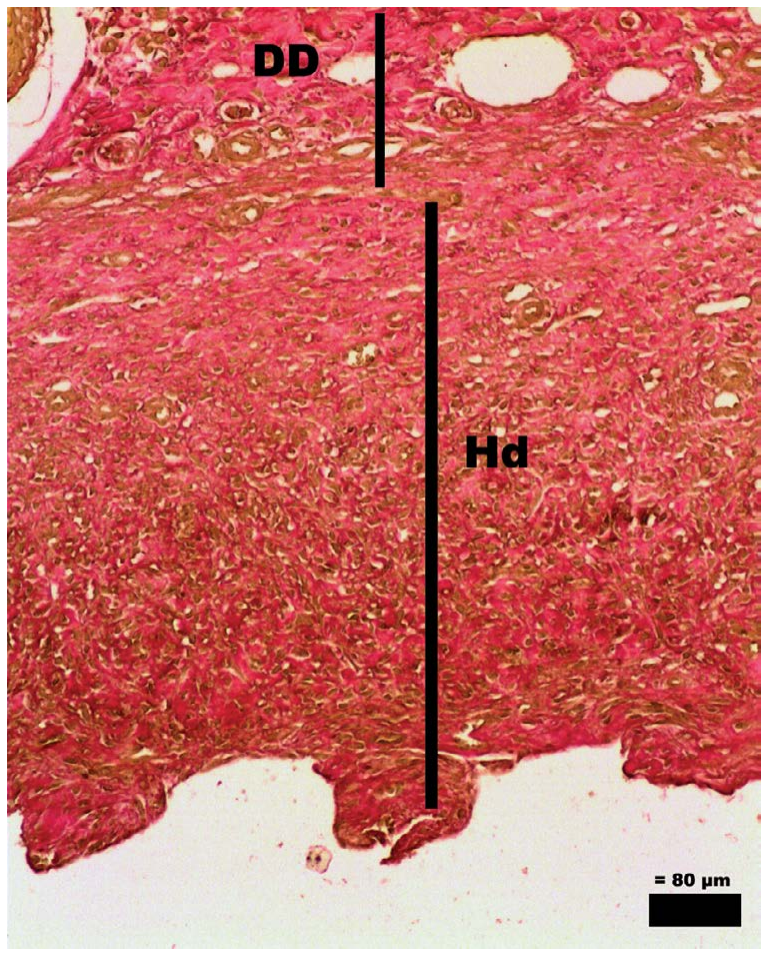

Figure 6. Antler velvet, adult deer. Van Gieson's stain. Note both collagen bundles and blood vessels are thicker in deep dermis (DD) than in hypodermis (Hd). Note fibrous projections with collagen bundles orientated perpendicular to the antler bone and richer in small vessels in hypodermis. Small venous lumina remain between fibrous projections. Magnification: $\times 100$. Bar $=80 \mu \mathrm{m}$.

cial dermis. However, in the vicinity of hair follicles and sebaceous glands, a thin layer of dermal connective tissue was present, with histological characteristics (fewer, thinner collagen bundles, abundant capillaries) which were quite similar to the superficial dermis.

The connective tissue in the antler hypodermis (Fig. 6) had abundant collagen bundles which were thinner than in the deep dermis, arteries and veins looked smaller, and the microvascular bed looked denser than in the deep dermis.

In the superficial dermis, collagen bundles showed no particular orientation, and traversed through the superficial dermis in all directions. However, at the limit between superficial and deep dermis, most bundles were parallel to the dermo-epidermal limit. In the deep dermis, most bundles were oblique to the dermo-epidermal limit. In the superficial papillary zone, most collagen bundles were oriented along the papillary axis and thus, approximately perpendicular to the epidermal surface, but almost parallel to the lateral papillary dermo-epidermal limit. Near hair follicles, collagen bundles were thinner than in the rest 
Table 1. Quantitative histological variables of antler velvet antler in adult and young pampas deer (Ozotoceros bezoarticus) males

\begin{tabular}{lccc}
\hline & Adult $(\mathbf{n}=\mathbf{4})$ & Juvenile $(\mathbf{n}=\mathbf{5})$ & $\mathbf{P}$ \\
\hline Epidermal thickness $[\mu \mathrm{m}]$ & $433.0 \pm 0.03$ & $359.0 \pm 16.3$ & 0.05 \\
Stratum basale $[\mu \mathrm{m}]$ & $125.0 \pm 0.3$ & $117.0 \pm 9.9$ & NS \\
Stratum intermedium $[\mu \mathrm{m}]$ & $265.0 \pm 0.05$ & $206.0 \pm 8.7$ & 0.09 \\
Stratum corneum $[\mu \mathrm{m}]$ & $43.0 \pm 0.02$ & $36.0 \pm 1.1$ & 0.04 \\
N of keratinocyte layers $[\mathrm{N}]$ & $4.0 \pm 0.2$ & $4.0 \pm 0.1$ & NS \\
Dermis thickness $[\mu \mathrm{m}]$ & $613.0 \pm 0.3$ & $643.0 \pm 30.5$ & NS \\
Superficial dermis $[\mu \mathrm{m}]$ & $52.0 \pm 0.07$ & $47.0 \pm 1.9$ & NS \\
Deep dermis $[\mu \mathrm{m}]$ & $561.0 \pm 0.3$ & $597.0 \pm 28.8$ & NS \\
\hline
\end{tabular}

Table 2. Main antler velvet quantitative histological parameters in adult and young pampas deer (Ozotoceros bezoarticus) males, and results of a multiple regression including the age and the days after antler casting as independent variables

\begin{tabular}{|c|c|c|c|c|c|}
\hline & $\begin{array}{l}\text { Pooled samples } \\
\qquad(\mathrm{n}=9)\end{array}$ & $\begin{array}{c}P \\
\text { of model }\end{array}$ & $\mathbf{R}^{2}$ & $\begin{array}{c}P \\
\text { of age }\end{array}$ & $\begin{array}{l}\text { P of days after } \\
\text { antler casting }\end{array}$ \\
\hline Epidermal thickness $[\mu \mathrm{m}]$ & $392.0 \pm 19.4$ & 0.04 & 0.67 & NS & NS \\
\hline Stratum basale $[\mu \mathrm{m}]$ & $121.0 \pm 5.8$ & NS & 0.32 & NS & NS \\
\hline Stratum intermedium $[\mu \mathrm{m}]$ & $232.0 \pm 16.6$ & 0.08 & 0.57 & NS & NS \\
\hline Stratum corneum $[\mu \mathrm{m}]$ & $39.0 \pm 1.8$ & 0.11 & 0.52 & 0.05 & NS \\
\hline $\mathrm{N}$ of keratinocyte layers [N] & $4.0 \pm 0.1$ & NS & 0.31 & NS & NS \\
\hline Dermis thickness $[\mu \mathrm{m}]$ & $630.0 \pm 28.5$ & NS & 0.13 & NS & NS \\
\hline Superficial dermis $[\mu \mathrm{m}]$ & $49.0 \pm 1.6$ & NS & 0.18 & NS & NS \\
\hline Deep dermis $[\mu \mathrm{m}]$ & $581.0 \pm 27.9$ & NS & 0.15 & NS & NS \\
\hline
\end{tabular}

of the deep dermis, and the bundles ran parallel to follicles and sebaceous glands.

Deeper into the deep dermis, collagen bundles were interwoven and more parallel to the velvet surface. The antler hypodermis had a thicker, more superficial, fibrous sector, where collagen bundles ran in all directions. Deeper inside the hypodermis, bundles of fibres became perpendicular to the velvet surface, as well as to the antler bone surface, where they inserted (insertions were cut during sampling). In these perpendicular bundles sectors, microvascular density seemed higher. Moreover, a venous layer, with fairly big lumina appeared interspersed with the insertion collagen bundles. All veins were sectioned when samples were taken, indicating they reached the limits of the antler bone tissue.

\section{Quantitative histological analysis}

Epidermal thickness and stratum corneum of AV was greater in adult than in yearling stags $(p<0.05$; Table 1). Stratum intermedium of AV from adult stags tended to be greater than in yearling stags $(p<0.09$; Table 1).

Age and days after antler casting positively influenced epidermal thickness ( $p=0.04$; Table 2 ), and tended to influence the stratum intermedium $(p=0.08)$ and the stratum corneum ( $p=0.1)$. In the stratum corneum, this tendency in the general model was generated by the positive influence of the age ( $p=0.05$; Table 2).

\section{DISCUSSION}

As far as we know, this is the first qualitative and quantitative report on deer's AV histology. In general, the main characteristics were similar to those of mammalian thin skin [22]. However, it was relevant to find several particular traits of velvet differing from skin: relatively thick epidermis (considering it is a type of thin skin sample), no evident papillae in most of the velvet, as expected for thin skin, but with shallow papillae in areas where epidermis is thicker, as well as an undulating pattern of epidermal thickness areas. 
Moreover, the stratum intermedium of the epidermis could be decomposed into a stratum spinosum and a stratum granulosum; both very thin but clearly distinct. This is not at all typical for thin skin [22], but reminds of thick skin samples [22]. Dermal characteristics also corresponded to those of thin skin. However, dermal irrigation was quite dense, regarding both microvascular and macrovascular vessels and, nevertheless, collagen bundles were thick and abundant in deep dermis. This seems a particularity of the AV histology, since normally densely woven collagen fibres do not coexist with abundant blood vessels [8]. Perhaps the mechanical demands of velvet, which is a thin structure overlying much harder antler bone, and the need for fast growth, explain this seemingly contradictory coexistence of a dense vascular bed and densely woven collagen fibres. Interestingly, Clark et al. [4] reported presence of pleiotropin mRNA both in the antler tip and in its velvet dermis. Pleiotropin is considered a strong angiogenic factor [9] and might explain the abundant dermal irrigation we are reporting. The complex and organised collagen bundle orientation might be an adaptation to mechanical stress of velvet along the antler surface.

Quantitative histological variables shed light to some interesting aspects of AV structure and the growth of the different layers. First of all, no layer had its thickness related directly to the time of sampling after antler cast, at least within the studied time ranges. Moreover, considering that the range in sampling time was wide in relation to the time during which velvet is still present (antlers are cast in August, attain maximum size in September, and $A V$ is shed in November; [27]), it can be assumed that the time during which the velvet has been developing is unrelated to the thickness of its layers. Interestingly, there was a relationship between age of the stag and stratum corneum thickness, but there was no relation with the stratum intermedium (just a tendency) or the stratum basale thickness, suggesting that the sloughing of superficial keratinocytes is slower in adult deer $\mathrm{AV}$, and/or superficial keratinocytes are thicker in adult deer AV. Perhaps this is explained by longer lasting intercellular unions between keratinocytes, but not higher mitotic rates at the stratum basale level, since differences were detected at the most superficial layers. However, to confirm this speculation, specific studies of mitotic rate should be performed. Overall, it would be interesting to study similar differences in animals with a wider age distribution. Interestingly, stratum corneum is thicker in adult stags, which develop heavier and bigger antlers as compared to their own body weight.

\section{CONCLUSIONS}

In summary, we have reported the first detailed qualitative and quantitative histological description of deer AV. The pampas deer AV's histological structure was similar to mammalian thin skin, but lacked sweat glands and arrector pili muscles; spinosum and granulosum strata could be recognised and the deep dermis was densely irrigated in spite of displaying abundant and well developed collagen bundles. The epidermal velvet thickness, as well as the stratum corneum thickness were both positively related to the age of the stags. On the other hand, the time since antler cast seemed not to influence the thickness of the different velvet layers.

\section{Acknowledgements}

Authors acknowledge Fernando Fumagalli, for anaesthetic management of animals and sampling the antler velvet. Financial support: CSIC-Universidad de la República and Intendencia Departamental de Maldonado, Uruguay.

\section{REFERENCES}

1. Barling PM, Lai AK, Nicholson LF. Distribution of EGF and its receptor in growing red deer antler. Cell Biol Int. 2005; 29: 229-236, doi: 10.1016/j.cellbi.2004.12.004.

2. Bhattacharyya TK. Skin aging in animal models: histological perspective. In: Farage MA, Miller KW, Mabach HI (eds.). Textbook of aging skin. Springer-Verlag, Berlin 2010: 5-12.

3. Bubenik GA, Miller KV, Lister AL, et al. Testosterone and estradiol concentrations in serum, velvet skin, and growing antler bone of male white-tailed deer. J Exp Zool A Comp Exp Biol. 2005; 303(3): 186-192, doi: 10.1002/jez.a.139, indexed in Pubmed: 15726635.

4. Clark DE, Lord EA, Suttie JM. Expression of VEGF and pleiotrophin in deer antler. Anat Rec A Discov Mol Cell Evol Biol. 2006; 288(12): 1281-1293, doi: 10.1002/ar.a.20393, indexed in Pubmed: 17054117.

5. Drew KR. Venison and other deer products. In: Brown RD (ed.). The Biology of Deer. Springer-Verlag, New York 1992: 225-232.

6. Drion PV, Hanzen C, Wirth D, et al. Physiologie de la reproduction et endocrinologie chez les cervidés: une revue. Ann Méd Vét. 2003; 147: 291-213.

7. Dryden G. Nutrition of antler growth in deer. Animal Production Science. 2016; 56(6): 962, doi: 10.1071/an15051.

8. Eurell JA, Van Si. Connective and Supportive Tissues. In: Frappier BL (eds.). Dellmann's Textbook of Veterinary Histology. Blackwell Publishing, Ames 2006: 31-59.

9. Fang W, Hartmann N, Chow DT, et al. Pleiotrophin stimulates fibroblasts and endothelial and epithelial cells and is 
expressed in human cancer. J Biol Chem. 1992; 267(36): 25889-25897, indexed in Pubmed: 1464602.

10. Fumagalli $F$, Villagrán $M$, Damián JP, et al. Physiological and biochemical parameters in response to electroejaculation in adult and yearling anesthetized pampas deer (Ozotoceros bezoarticus) males. Reprod Domest Anim. 2012; 47(2): 308-312, doi: 10.1111/j.1439-0531.2011.01859.x, indexed in Pubmed: 21762217.

11. Gilbey A, Perezgonzalez JD. Health benefits of deer and elk velvet antler supplements: a systematic review of randomised controlled studies. N Z Med J. 2012; 125(1367): 80-86, indexed in Pubmed: 23321886.

12. Jackson JE, Langguth $A$. Ecology and status of pampas deer (Ozotoceros bezoarticus) in the Argentinean pampas and Uruguay. In: Wemmer C (ed.) Biology and management of the Cervidae. Smithsonian Institution Press, Washington DC 1987: 402.

13. Kuo CY, Wang T, Dai TY, et al. Effect of the Velvet Antler of Formosan Sambar Deer (Cervus unicolor swinhoei) on the Prevention of an Allergic Airway Response in Mice. Evid Based Complement Alternat Med. 2012; 2012: 481318, doi: 10.1155/2012/481318, indexed in Pubmed: 23346203.

14. Li C. Histogenetic aspects of deer antler development. Front Biosci (Elite Ed). 2013; 5: 479-489, doi: 10.2741/ E629, indexed in Pubmed: 23277003.

15. Li C, Suttie JM, Clark DE. Histological examination of antler regeneration in red deer (Cervus elaphus). Anat Rec, A 282A. 2005: 163-174, doi: 10.1002/ar.a.20148.

16. Lu C, Wang M, Mu J, et al. Simultaneous determination of eighteen steroid hormones in antler velvet by gas chromatography-tandem mass spectrometry. Food Chem. 2013; 141(3): 1796-1806, doi: 10.1016/j.foodchem.2013.04.104, indexed in Pubmed: 23870893.

17. Malo AF, Roldan ERS, Garde JJ, et al. What does testosterone do for red deer males? Proc Biol Sci. 2009; 276: 971-980, doi: 10.1098/rspb.2008.1367.

18. Moreau M, Dupuis J, Bonneau NH, et al. Clinical evaluation of a powder of quality elk velvet antler for the treatment of osteoarthrosis in dogs. Can Vet J. 2004; 45(2): 133-139, doi: 10.1098/rspb.2008.1367, indexed in Pubmed: 15025149.

19. Muir PD, Sykes AR, Barrell GK. Changes in blood content and histology during growth of antlers in red deer (Cervus elaphus) and their relationship to plasma testosterone levels. J Anat. 1988; 158: 31-42.

20. Pita-Thomas W, Fernández-Martos C, Yunta M, et al. Gene expression of axon growth promoting factors in the deer antler. PLoS One. 2010; 5(12): e15706, doi: 10.1371/ journal.pone.0015706, indexed in Pubmed: 21187928.

21. Price J, Allen S. Exploring the mechanisms regulating regeneration of deer antlers. Philos Trans $\mathrm{R}$ Soc Lond B Biol Sci. 2004; 359(1445): 809-822, doi: 10.1098/ rstb.2004.1471, indexed in Pubmed: 15293809.

22. Scott DW, Miller WH, Griffin CE. Muller and Kirk's Small Animal Dermatology. 6th ed. WB Saunders, Philadelphia 2001.
23. Sui Z, Zhang L, Huo $Y$, et al. Bioactive components of velvet antlers and their pharmacological properties. J Pharm Biomed Anal. 2014; 87: 229-240, doi: 10.1016/j. jpba.2013.07.044, indexed in Pubmed: 24029381.

24. Tseng SH, Sung CH, Chen LG, et al. Comparison of chemical compositions and osteoprotective effects of different sections of velvet antler. J Ethnopharmacol. 2014; 151(1): 352-360, doi: 10.1016/j.jep.2013.10.060, indexed in Pubmed: 24212078.

25. Tseng SH, Sung HC, Chen LG, et al. Effects of velvet antler with blood on bone in ovariectomized rats. Molecules. 2012; 17(9): 10574-10585, doi: 10.3390/ molecules170910574, indexed in Pubmed: 22951396.

26. Ungerfeld R, González-Pensado S, Bielli A, et al. Reproductive biology of the pampas deer (Ozotoceros bezoarticus): a review. Acta Vet Scand. 2008; 50: 16, doi: 10.1186/17510147-50-16, indexed in Pubmed: 18534014.

27. Ungerfeld R, González-Sierra U, Bielli A. Seasonal antler cycle in a herd of pampas deer (Ozotoceros bezoarticus) in Uruguay. Mammalian Biology - Zeitschrift für Säugetierkunde. 2008; 73(5): 388-391, doi: 10.1016/j. mambio.2007.08.006.

28. Ungerfeld R, González-Pensado S, Bielli A, et al. Reproductive biology of the pampas deer (Ozotoceros bezoarticus). Mamm Biol. 2008; 73: 478-481, doi: 10.1186/17510147-50-16.

29. Ungerfeld R, Villagrán M, González-Pensado S. Antler weight and body weight relationship in adult and young pampas deer (Ozotoceros bezoarticus) males. North West J Zool. 2011; 7: 208-212.

30. Van den Berg GHJ, Garrick D. Inheritance of adult velvet antler weights and live weights in farmed red deer. Livest Prod Sci. 1997; 49: 287-295, doi: 10.1016/S03016226(97)00044-4.

31. Vitellaro-Zuccarello L, Cappelletti S, Dal Pozzo Rossi V, et al. Stereological analysis of collagen and elastic fibers in the normal human dermis: variability with age, sex, and body region. Anat Rec. 1994; 238(2): 153-162, doi: 10.1002/ ar.1092380202, indexed in Pubmed: 8154602.

32. Wu F, Li H, Jin L, et al. Deer antler base as a traditional Chinese medicine: a review of its traditional uses, chemistry and pharmacology. J Ethnopharmacol. 2013; 145(2): 403-415, doi: 10.1016/j.jep.2012.12.008, indexed in Pubmed: 23246455.

33. Zhang M, Li Na, Qu X, et al. Total velvet-antler polypeptide extract from Cervus nippon Temminck induces cell proliferation and activation of the PI3K-Akt signalling pathway in human peripheral blood lymphocytes. Animal Production Science. 2016; 56(6): 1008, doi: 10.1071/ an15103.

34. Zhang LZ, Xin JL, Zhang XP, et al. The anti-osteoporotic effect of velvet antler polypeptides from Cervus elaphus Linnaeus in ovariectomized rats. J Ethnopharmacol. 2013; 150(1): 181-186, doi: 10.1016/j.jep.2013.08.029, indexed in Pubmed: 23993908. 